\title{
Dynamic Response of a Gantry Crane's Beam Subjected to a Two-Axle Moving Trolley
}

\author{
Qingrong Chen, ${ }^{1,2}$ Wenming Cheng $\mathbb{D}^{1,2}$ Lingchong Gao, ${ }^{3}$ and Run Du $\mathbb{D}^{1,2}$ \\ ${ }^{1}$ School of Mechanical Engineering, Southwest Jiaotong University, Chengdu 610031, China \\ ${ }^{2}$ Technology and Equipment of Rail Transit Operation and Maintenance Key Laboratory of Sichuan Province, \\ Chengdu 610031, China \\ ${ }^{3}$ Chair of Materials Handling, Material Flow, Logistics, Technical University of Munich, Garching 85748, Germany
}

Correspondence should be addressed to Run Du; rdu@swjtu.edu.cn

Received 28 March 2020; Revised 1 June 2020; Accepted 6 June 2020; Published 9 July 2020

Academic Editor: Francesco Franco

Copyright (c) 2020 Qingrong Chen et al. This is an open access article distributed under the Creative Commons Attribution License, which permits unrestricted use, distribution, and reproduction in any medium, provided the original work is properly cited.

\begin{abstract}
In this paper, a novel moving load model for 2D crane systems of which the trolley has two axles is proposed. Based on this model, the dynamics of a 2D gantry crane, which is modelled as a simply supported Euler-Bernoulli beam carrying a two-axle trolley from which a single-pendulum payload is suspended, is studied. The proposed model was verified by comparing with two models in existing papers and can be considered as an extended version of comparative models. Then, the effect of the trolley's axle base on the dynamic responses of the beam is studied. It can be observed that increasing the length of trolley's axle base will decrease the deflection of the beam, and a larger initial swing angle will cause a larger deflection of the beam without controlling the swing of the payload.
\end{abstract}

\section{Introduction}

Industrial crane systems, which are a class of representative nonlinear systems, play an important role in modern industries. They can be modelled as a coupled system of moving payload and flexible beam. Vibration is a serious problem in the applications of crane systems because the structural flexibility will certainly affect the behaviour of the controller leading to precise positioning problems of the trolley and payload [1]. For instance, in the metallurgical industry, it has not only a high demand for horizontal positioning accuracy of the crane transport but also a high demand for height positioning accuracy of the payload. It is well known that a larger span will cause a larger deflection of the main beam of crane systems while the cross section and the payload mass keep unchanged. Therefore, with the increase of crane span, the dynamic responses of the main beam cannot be neglected.

Many researchers used the assumed mode method to establish the dynamic model of overhead crane systems [2-5] and quayside container crane systems [6]. It is found that the value of the beam deflection increases by increasing the total mass of the trolley and payload [2-4]. In [2], the authors also found that, for given masses of the trolley and payload, the location and the value of the maximum beam deflection are dependent upon the trolley speed. In [4], it is observed that the mass of the driver's cabin has little effect on the deflection of the beam, but its position has obvious effect. In [5], it is found that the swing response of the payload is not sensitive to the stiffness of the beam. Some researchers applied the finite element method to study the transverse and longitudinal vibrations of the flexible beam of crane systems [7, 8]. In [7], the cable is considered as an elastic body, and the authors found that increase of trolley speed and acceleration/deceleration do not have significant influence for vertical displacements, but have on horizontal displacements. In [8], the author presented a technique to replace the moving load by an equivalent moving finite element. They demonstrated the effect of the cable length, the trolley mass, and the velocity of the trolley on the deflection of the beam.

In the aforementioned papers, the trolley is modelled as a particle/mass point. That means there is only one contact point between the trolley and the flexible beam. However, a trolley has at least four wheels in contact with the flexible beam. If we consider it as a planar model, it can be reduced to a two-axle model. In the field of vehicle-bridge coupling system, many 
researchers studied the dynamic responses of bridges/beams subjected to moving vehicles with two axles [9-11]. In these papers, vehicles are in contact with the beams through two wheels, and the assumed mode method is adopted to derive the deflections of the beams. Inspired by [9-11], we proposed a novel moving load model for $2 \mathrm{D}$ crane systems of which the trolley has two axles. This new model can provide more accurate results of the dynamic responses of the crane beam.

The rest parts of the paper are structured as follows. Section 2 presents the new dynamic model of the crane system. Section 3 validates the accuracy of the mathematical model by comparing it with several existing models and analyses the effect of the trolley's axle base. Section 4 draws the conclusions of the entire paper.

\section{Dynamic Modelling}

2.1. Crane System Description. Figure 1 shows the overview of a L-type single-beam gantry crane, and Figure 2 shows the $2 \mathrm{D}$ schematic of the L-type single-beam gantry crane. In the 2D schematic, the trolley has two wheels in contacting with the beam. The full length of the beam is $L$, the distance between two legs is $L_{0}$, and the length of the cantilever is $L_{1}$. When the trolley reaches the limit position on the cantilever, the distance between the centre of the trolley and the centre line of the supporting leg is $L_{2}$. The mass per unit length of the beam is $\rho$, the cross-sectional moment of inertia is $I$, and Young's modulus is $E$.

Figure 3 shows the schematic diagram of the coupling dynamics modelling of the crane system. $O_{1}$ and $O_{2}$ are support points simplifying for the supported legs. $A_{1}$ and $A_{2}$ are the end points of the cantilever. $B_{1}$ and $B_{2}$ are the limit positions of the centre of the trolley. The mass of the trolley is denoted as $m_{c}$, the axle base of the trolley is $d$, the contact forces between the trolley and the beam are $P_{1}$ and $P_{2}$, the length of the cable is $l$, the mass of the payload is $m_{\mathrm{p}}$, and the sway angle of the payload is $\theta$.

2.2. Modelling. The following assumptions are made before the modelling:

(1) Compared with the payload's mass, the mass of the cable connecting the payload and trolley can be ignored, and the cable is always in a tight state due to the effect of the payload. Therefore, the cable is considered massless and rigid, and the payload sways as a single pendulum.

(2) The dynamic responds of the support legs are not considered, and support points of the main beam are simplified as pin-pin supports.

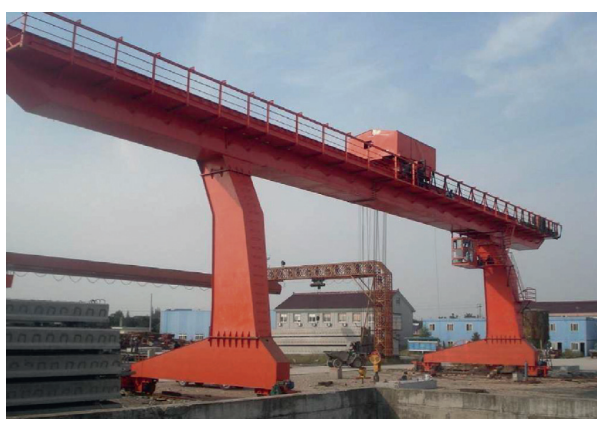

Figure 1: The overview of a L-type single-beam gantry crane.

(3) The cantilevers $\left(O_{1}-A_{1}\right.$ and $\left.O_{2}-A_{2}\right)$ are considered as rigid beams because their displacements subjected to the moving trolley are small. The part of the main beam between two legs $\left(O_{1}-O_{2}\right)$ is modelled as a simply supported Euler-Bernoulli beam.

(4) The cross section of the beam is constant.

(5) It is assumed that the trolley is always in contact with the top beam. The centre of the trolley has a constant distance $h$ from the beam top surface. The rotating movement around the centre of mass of the trolley is not considered.

In this paper, based on these assumptions, the part of the main beam $\mathrm{O}_{1}-\mathrm{O}_{2}$ is considered as simply supported, and the general solution of its shape function is

$$
\phi(x)=C_{1} \cos \beta x+C_{2} \sin \beta x+C_{3} \cosh \beta x+C_{4} \sinh \beta x,
$$

with pined-pined boundary conditions

$$
\phi(0)=0, \phi^{\prime \prime}(0)=0, \phi\left(L_{0}\right)=0, \phi^{\prime \prime}\left(L_{0}\right)=0 .
$$

Then, the $i$ th model shape function of the simply supported beam is derived as

$$
\phi_{i}(x)=\sin \left(\frac{i \pi x}{L_{0}}\right) .
$$

The vertical displacement of the beam can be expressed as

$$
y_{b}=w(x, t)=\sum_{i=1}^{n} \phi_{i}(x) q_{i}(t) .
$$

The coordinates of the centre of the trolley are

$$
\left\{\begin{array}{l}
x_{c}=\frac{1}{2}\left(x_{1}+x_{2}\right), \\
y_{c}=\frac{1}{2}\left(w\left(x_{1}, t\right)+w\left(x_{2}, t\right)\right)+h=\frac{1}{2} \sum_{i=1}^{n}\left(\phi_{i}\left(x_{1}\right)+\phi_{i}\left(x_{2}\right)\right) q_{i}(t)+h .
\end{array}\right.
$$




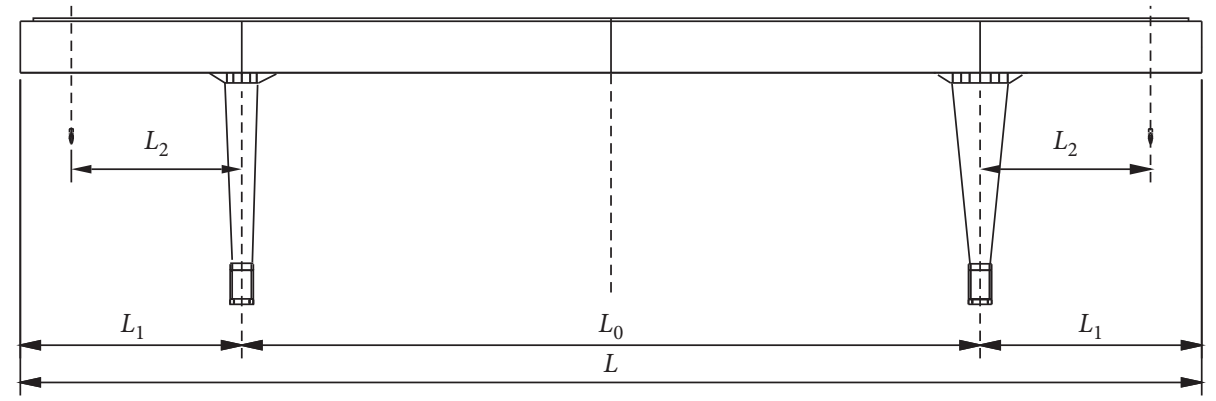

Figure 2: The 2D schematic diagram of the L-type single-beam gantry crane.

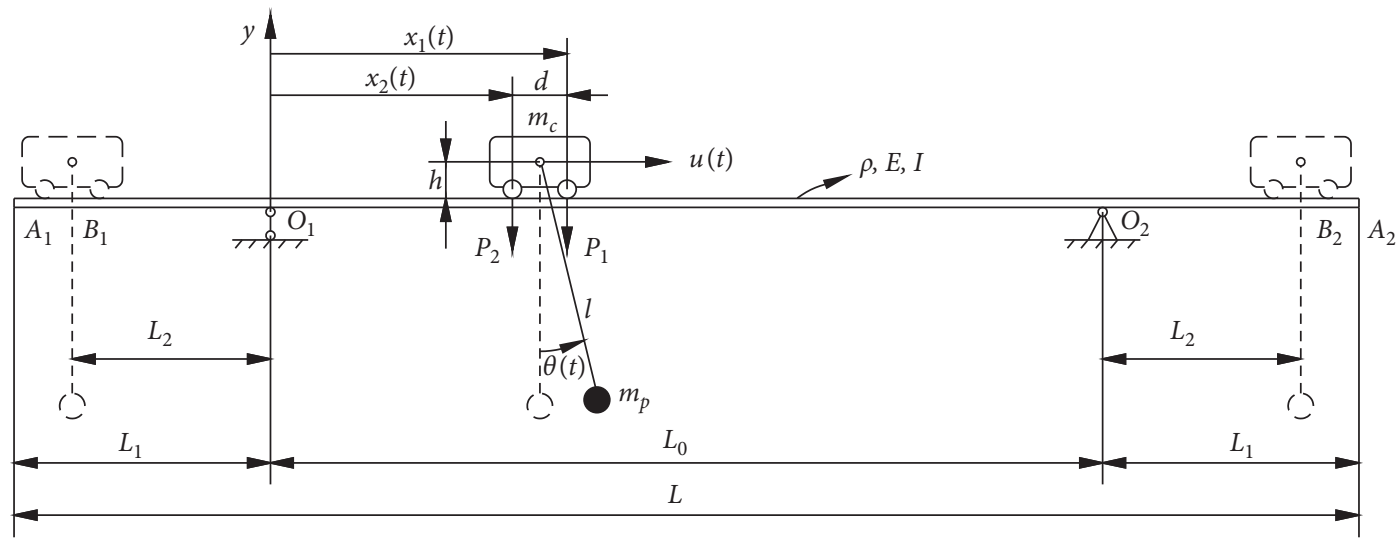

FIGURE 3: The schematic diagram of the coupling dynamics modelling of the crane system.

The horizontal velocity of the centre of the trolley is

$$
\dot{x}_{c}=\dot{x}_{1}=\dot{x}_{2} \text {. }
$$

And the vertical velocity is

$$
\begin{aligned}
\dot{y}_{c} & =\frac{1}{2}\left(\frac{\mathrm{d} w\left(x_{1}, t\right)}{\mathrm{d} t}+\frac{\mathrm{d} w\left(x_{2}, t\right)}{\mathrm{d} t}\right) \\
& =\frac{1}{2} \sum_{i=1}^{n}\left(\dot{x}_{1} \phi_{i}^{\prime}\left(x_{1}\right) q_{i}+\phi_{i}\left(x_{1}\right) \dot{q}_{i}+\dot{x}_{2} \phi_{i}^{\prime}\left(x_{2}\right) q_{i}+\phi_{i}\left(x_{2}\right) \dot{q}_{i}\right) \\
& =\frac{1}{2} \sum_{i=1}^{n}\left(\dot{x}_{1} \phi_{i}^{\prime}\left(x_{1}\right)+\dot{x}_{2} \phi_{i}^{\prime}\left(x_{2}\right)\right) q_{i}+\frac{1}{2} \sum_{i=1}^{n}\left(\phi_{i}\left(x_{1}\right)+\phi_{i}\left(x_{2}\right)\right) \dot{q}_{i} .
\end{aligned}
$$

The acceleration of trolley is known and expressed as

$$
\ddot{x}_{c}=\ddot{x}_{1}=\ddot{x}_{2}=a \text {. }
$$

The kinetic energy of the flexible beam, trolley, and payload are denoted by $T_{\mathrm{b}}, T_{\mathrm{c}}$, and $T_{\mathrm{p}}$, respectively, which can be calculated as follows:

$$
T_{\mathrm{b}}=\frac{1}{2} \int_{0}^{L} \rho\left(\frac{\partial y_{\mathrm{b}}}{\partial t}\right)^{2} \mathrm{~d} x
$$

$$
\begin{aligned}
& =\frac{1}{2} \int_{0}^{L} \rho\left(\sum_{i=1}^{n} \phi_{i}(x) \dot{q}_{i}(t)\right)^{2} \mathrm{~d} x \\
& =\frac{1}{2} \sum_{i=1}^{n} \sum_{j=1}^{n} \dot{q}_{i}(t) \dot{q}_{j}(t) \int_{0}^{L} \rho \phi_{i}(x) \phi_{j}(x) \mathrm{d} x,
\end{aligned}
$$$$
T_{\mathrm{c}}=\frac{1}{2} m_{\mathrm{c}}\left(\dot{x}_{\mathrm{c}}^{2}+\dot{y}_{\mathrm{c}}^{2}\right) \text {, }
$$

$$
T_{\mathrm{p}}=\frac{1}{2} m_{\mathrm{p}}\left(\left(\dot{x}_{\mathrm{c}}+l \dot{\theta} \cos \theta\right)^{2}+\left(\dot{y}_{c}-\dot{l} \dot{\theta} \sin \theta\right)^{2}\right) .
$$

Then, the total kinetic energy of the coupled system can be obtained:

$$
T=T_{\mathrm{b}}+T_{\mathrm{c}}+T_{\mathrm{p}}
$$

The potential energy of the flexible beam, trolley, and payload are denoted by $V_{\mathrm{b}}, V_{\mathrm{c}}$, and $V_{\mathrm{p}}$, respectively, which can be calculated as follows: 


$$
\begin{aligned}
V_{b}= & \frac{1}{2} \int_{0}^{L} E I\left(\frac{\partial^{2} y_{b}}{\partial x^{2}}\right)^{2} \mathrm{~d} x \\
& =\frac{1}{2} \int_{0}^{L} E I\left(\sum_{i=1}^{n} \phi_{i}^{\prime \prime}(x) q_{i}(t)\right)^{2} \mathrm{~d} x \\
& =\frac{1}{2} \sum_{i=1}^{n} \sum_{j-1}^{n} q_{i}(t) q_{j}(t) \int_{0}^{L} E I \phi_{i}^{\prime \prime}(x) \phi_{j}^{\prime \prime}(x) \mathrm{d} x, \\
V_{c} & =-m_{c} g y_{c},
\end{aligned}
$$

$$
V_{p}=-m_{p} g\left(y_{c}+l \cos \theta\right)
$$

Then, the total potential energy of the coupled system can be obtained:

$$
V=V_{b}+V_{c}+V_{p}
$$

By applying the Lagrange equation,

$$
\frac{\mathrm{d}}{\mathrm{d} t} \frac{\partial T}{\partial \dot{q}_{i}}-\frac{\partial T}{\partial q_{i}}+\frac{\partial V}{\partial q_{i}}=0, \quad i=1,2, \ldots, n,
$$

one can derive the dynamic equation of the generalized coordinate $q_{i}$ :

$$
\begin{aligned}
& \frac{1}{4}\left(m_{c}+m_{p}\right)\left(\phi_{i}\left(x_{1}\right)+\phi_{i}\left(x_{2}\right)\right) \sum_{j=1}^{n}\left(\ddot{x}_{1} \phi_{j}^{\prime}\left(x_{1}\right)+\dot{x}_{1}^{2} \phi_{j}^{\prime \prime}\left(x_{1}\right)+\ddot{x}_{2} \phi_{j}^{\prime}\left(x_{2}\right)+\dot{x}_{2}^{2} \phi_{j}^{\prime \prime}\left(x_{2}\right)\right) q_{j} \\
& \quad+\frac{1}{4}\left(m_{c}+m_{p}\right)\left(\phi_{i}\left(x_{1}\right)+\phi_{i}\left(x_{2}\right)\right) \sum_{j=1}^{n}\left(2\left(\dot{x}_{1} \phi_{j}^{\prime}\left(x_{1}\right)+\dot{x}_{2} \phi_{j}^{\prime}\left(x_{2}\right)\right) \dot{q}_{j}+\left(\phi_{j}\left(x_{1}\right)+\phi_{j}\left(x_{2}\right)\right) \ddot{q}_{j}\right) \\
& \quad+\sum_{j=1}^{n} \int_{0}^{L} \rho \phi_{i}(x) \phi_{j}(x) \mathrm{d} x \ddot{q}_{j}(t)-\frac{1}{2} m_{p} l\left(\phi_{i}\left(x_{1}\right)+\phi_{i}\left(x_{2}\right)\right) \\
& \quad \cdot\left(\ddot{\theta} \sin \theta+\dot{\theta}^{2} \cos \theta\right)+\sum_{j=1}^{n} \int_{0}^{L} E I \phi_{i}^{\prime \prime}(x) \phi_{j}^{\prime \prime}(x) \mathrm{d} x q_{j}(t)-\frac{1}{2}\left(m_{c}+m_{p}\right) g\left[\phi_{i}\left(x_{1}\right)+\phi_{i}\left(x_{2}\right)\right]=0 .
\end{aligned}
$$

By applying the Lagrange equation,

$$
\frac{\mathrm{d}}{\mathrm{d} t} \frac{\partial T}{\partial \dot{\theta}}-\frac{\partial T}{\partial \theta}+\frac{\partial V}{\partial \theta}=0
$$

one can derive the dynamic equation of the generalized coordinate $\theta$.

$$
\begin{aligned}
& -\frac{1}{2} m_{p} l \sin \theta \cdot \sum_{j=1}^{n}\left(\ddot{x}_{1} \phi_{j}^{\prime}\left(x_{1}\right)+\dot{x}_{1}^{2} \phi_{j}^{\prime \prime}\left(x_{1}\right)+\ddot{x}_{2} \phi_{j}^{\prime}\left(x_{2}\right)+\dot{x}_{2}^{2} \phi_{j}^{\prime \prime}\left(x_{2}\right)\right) q_{j} \\
& -\frac{1}{2} m_{p} l \sin \theta \cdot \sum_{j=1}^{n}\left(2\left(\dot{x}_{1} \phi_{j}^{\prime}\left(x_{1}\right)+\dot{x}_{2} \phi_{j}^{\prime}\left(x_{2}\right)\right) \dot{q}_{j}+\left(\phi_{j}\left(x_{1}\right)+\phi_{j}\left(x_{2}\right)\right) \ddot{q}_{j}\right) \\
& +m_{p} l\left(\ddot{x}_{c} \cos \theta+\ddot{\theta}\right)+m_{p} g l_{1} \sin \theta=0 .
\end{aligned}
$$

Equations (18) and (20) compose the dynamic equation of the coupled system.

\section{Simulation Results and Discussion}

In this paper, Newmark- $\beta$ method was used to solve the numerical solution of the dynamic models (18) and (20). The integration time step was $0.001 \mathrm{~s}$. The initial position of the trolley is $x_{1}=0$ and $x_{2}=-d$ (see Figure 3), and the trolley stops at position $x_{1}=L_{0}+d$ and $x_{2}=L_{0}$. All parameters are listed in Table 1.
3.1. Validation of the Proposed Model. To validate the proposed model, a moving mass model (without payload) [4] and a moving trolley model (the trolley is simplified as a particle/mass point) [12] were adopted.

3.1.1. Results Compared with [4]. If the payload swing and the axle base of the trolley are equal to 0 , i.e., $\theta, d=0$, equation (18) describes a simply supported beam subjected to a moving mass. For the system parameters, refer to Case A in Table 1 . The velocity of the moving load is constant and its value is $3.34 \mathrm{~m} / \mathrm{s}$. The simulation results are shown in Figure 4. 
TABLE 1: System parameters.

\begin{tabular}{lccc}
\hline Parameters & Case A & Case B & Case C \\
\hline$E\left(\mathrm{~N} / \mathrm{m}^{2}\right)$ & $2.07 \times 10^{11}$ & $2.15 \times 10^{11}$ & $2.06 \times 10^{11}$ \\
$I\left(\mathrm{~m}^{4}\right)$ & $1.04 \times 10^{-6}$ & 0.8 & 0.0643 \\
$\rho(\mathrm{kg} / \mathrm{m})$ & 7.04 & $1.53 \times 10^{3}$ & 599.64 \\
$L_{0}(\mathrm{~m})$ & 10 & 100 & 50 \\
$L_{1}(\mathrm{~m})$ & 0 & 0 & 10 \\
$L_{2}(\mathrm{~m})$ & 0 & 0 & 0 \\
$m_{\mathrm{c}}(\mathrm{kg})$ & 70 & $3.06 \times 10^{4}$ & $13.165 \times 10^{3}$ \\
$m_{\mathrm{p}}(\mathrm{kg})$ & 0 & $3.06 \times 10^{4}$ & $36 \times 10^{3}$ \\
$l(\mathrm{~m})$ & 0 & 5 & 5 \\
$g\left(\mathrm{~m} / \mathrm{s}^{2}\right)$ & 9.8 & 9.8 & 9.8 \\
\hline
\end{tabular}

Figure 4 shows the time histories of the midspan deflections of the simply supported beam. The assumed mode method is used to solve the deflections of the beam in both [4] and this paper. As can be seen from Figure 4, the maximum deflection of the midspan is $0.0694 \mathrm{~m}$, and the calculation results of the proposed model are consistent with those of [4].

3.1.2. Results Compared with [12]. If the axle base of the trolley is equal to 0 , i.e., $d=0$, equations (18) and (20) describe a simply supported beam subjected to a moving trolley suspended with a single-pendulum payload. In this case, the trolley is simplified as a mass point. For the system parameters, refer to Case B in Table 1. The simulation results are shown in Figure 5. For Figures 5(a)-5(c), the initial velocities of the trolley are 0 , while the accelerations are 1,2 , and $3 \mathrm{~m} / \mathrm{s}^{2}$, respectively.

It can be observed that the values of the maximum midspan deflection of the beam in Figures 5(a)-5(c) are $0.0751,0.0762$, and $0.0862 \mathrm{~m}$, respectively. That means the maximum midspan deflection of the beam will increase as the acceleration of the trolley increases. It can be also found that the calculation results of the proposed model are consistent with those of [12].

In summary, it can be easily found from Figures 4 and 5 that the simulation results of this paper are quite consistent with that of $[4,12]$. Therefore, the dynamic model developed in this paper is considered as an acceptable model for calculating the dynamic responses of a crane system. Besides, the trolley's axle base is equal to 0 in $[4,12]$ and the payload swing angle is also equal to 0 in [4], so the proposed model can be considered as an extended version of the models in $[4,12]$. In other words, the proposed model is downward compatible with those in $[4,12]$.

3.2. Effect of the Trolley's Axle Base. In this section, we study the effect of the trolley's axle base under zero initial swing angle condition and nonzero initial swing angle condition. At the beginning of the simulation, the initial velocity of the trolley is 0 . The trolley accelerates at a constant acceleration of $0.15 \mathrm{~m} / \mathrm{s}^{2}$. Then, it runs at a constant speed at the maximum speed. Finally, it uniformly decelerates to a standstill. The acceleration and deceleration time are both

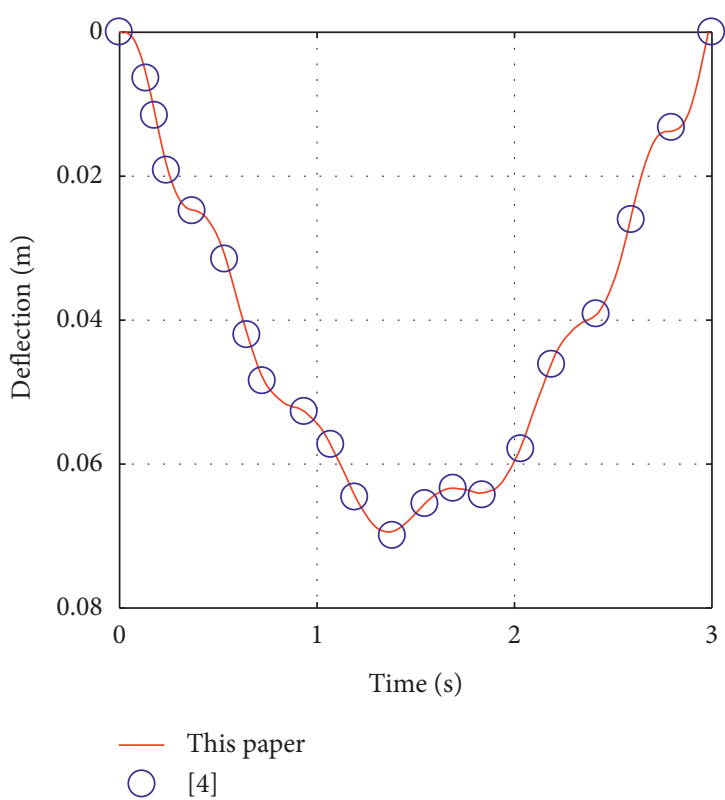

FIgURE 4: The midspan deflections of the beam compared with [4].

$6.67 \mathrm{~s}$. For the system parameters, refer to Case C in Table 1.

3.2.1. Zero Initial Swing Angle Condition. For comparison study, we choose three control groups as follows:

Case C-I: $d=4 \mathrm{~m}$ and $\theta=0 \mathrm{rad}$

Case C-II: $d=2 \mathrm{~m}$ and $\theta=0 \mathrm{rad}$

Case C-III: $d=0 \mathrm{~m}$ and $\theta=0 \mathrm{rad}$

The simulation results are shown in Figures 6 and 7. Figure 6 shows the midspan deflections with regard to time. From Figure 6, it can be easily found that the maximum midspan deflection in Case C-II $(0.0946 \mathrm{~m})$ is slightly smaller than that in Case C-III $(0.0947 \mathrm{~m})$, and the maximum midspan deflection in Case C-I $(0.0940 \mathrm{~m})$ is the minimum among three cases. Figure 7 shows the relationship between the vertical displacements of the centre of the trolley and the position of the centre of the trolley. Suppose that the initial displacement of the trolley is 0 . Due to the different axle bases, the midspan deflections and displacements of the trolley were quite different among three cases at the initial and final phases of the simulation. It can be easily found that the larger the axle base, the smaller the displacement of the trolley.

3.2.2. Nonzero Initial Swing Angle Condition. In previous research studies, the effect of the initial swing angle is not considered, i.e., at the beginning of the simulation, the swing angle is set to 0 . In practice, a large swing angle should be avoided as much as possible because there is a risk of dangerous accidents. 


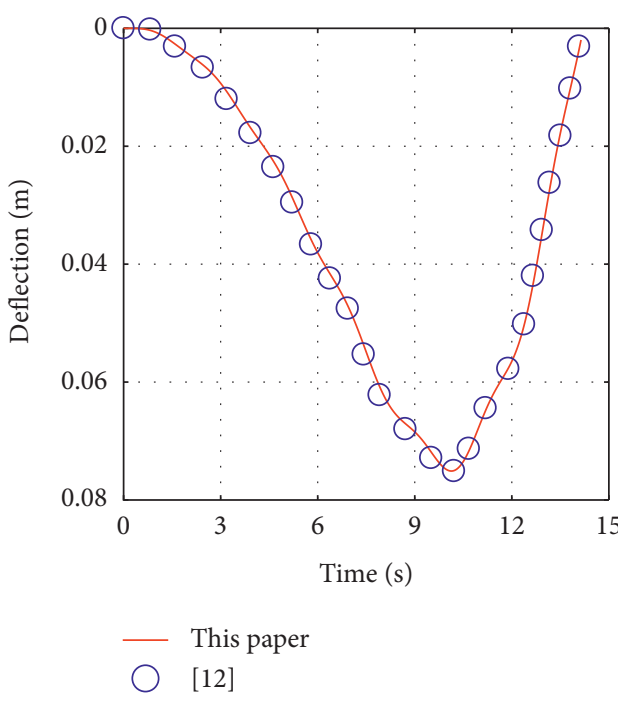

(a)

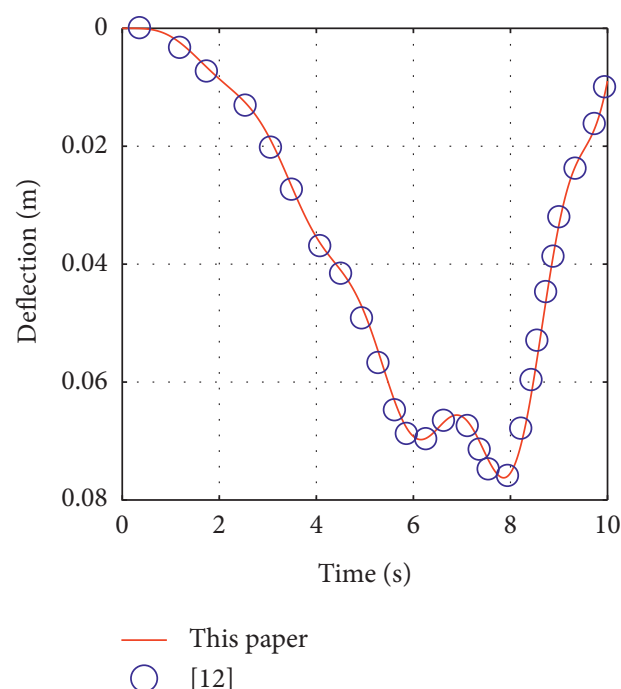

(b)

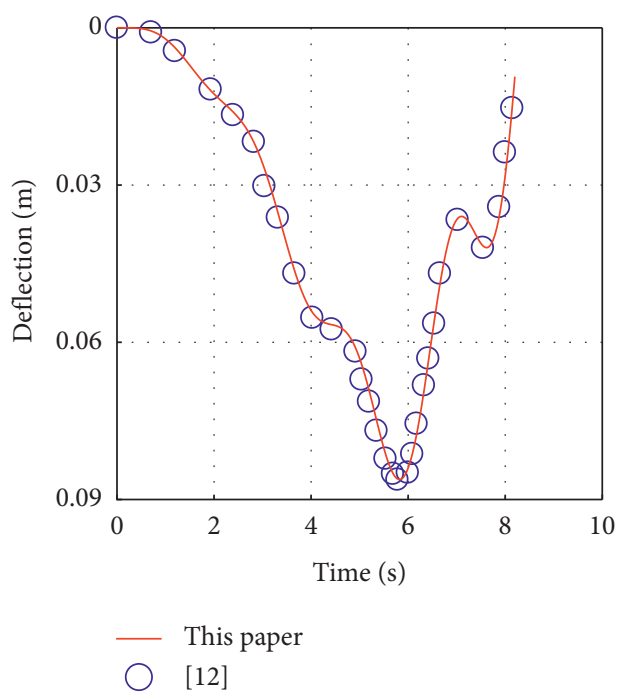

(c)

FIgURe 5: The midspan deflections of the beam compared with [12].

For comprehensive understanding of initial swing angle effects, we choose the following three nonzero initial swing angle cases for comparison study:

Case C-IV: $d=4 \mathrm{~m}$ and $\theta=0.1 \mathrm{rad}$

Case C-V: $d=2 \mathrm{~m}$ and $\theta=0.1 \mathrm{rad}$

Case C-VI: $d=0 \mathrm{~m}$ and $\theta=0.1 \mathrm{rad}$

The simulation results are shown in Figures 8 and 9 . From Figure 8 , it can be easily found that, regarding the maximum midspan deflection, Case $\mathrm{C}$-VI has the maximum value $(0.0958 \mathrm{~m})$, following Case $\mathrm{C}-\mathrm{V}(0.0954 \mathrm{~m})$, and Case $\mathrm{C}$-IV has the minimum value $(0.0949 \mathrm{~m})$. From Figure 9 , one can obtain that the larger the axle base, the smaller the vertical displacement of the trolley, too.
To further study the effect of the initial swing angle of the payload on the midspan deflection of the beam, the following two cases were added:

Case C-VII: $d=4 \mathrm{~m}$ and $\theta=0.2 \mathrm{rad}$

Case C-VIII: $d=4 \mathrm{~m}$ and $\theta=0.3 \mathrm{rad}$

From Figure 10, one can observe that Case C-I has the minimum value of the maximum midspan deflection of the beam $(0.0940 \mathrm{~m})$, following Case C-IV $(0.0949 \mathrm{~m})$ and Case VII $(0.0977 \mathrm{~m})$, and Case C-VIII has the maximum value $(0.1018 \mathrm{~m})$.

Thus, as the initial swing angle increased, the maximum midspan deflection of the beam increased. As shown in Figure 11, the vertical displacement of the centre of the trolley increased as the initial swing angle increased. 


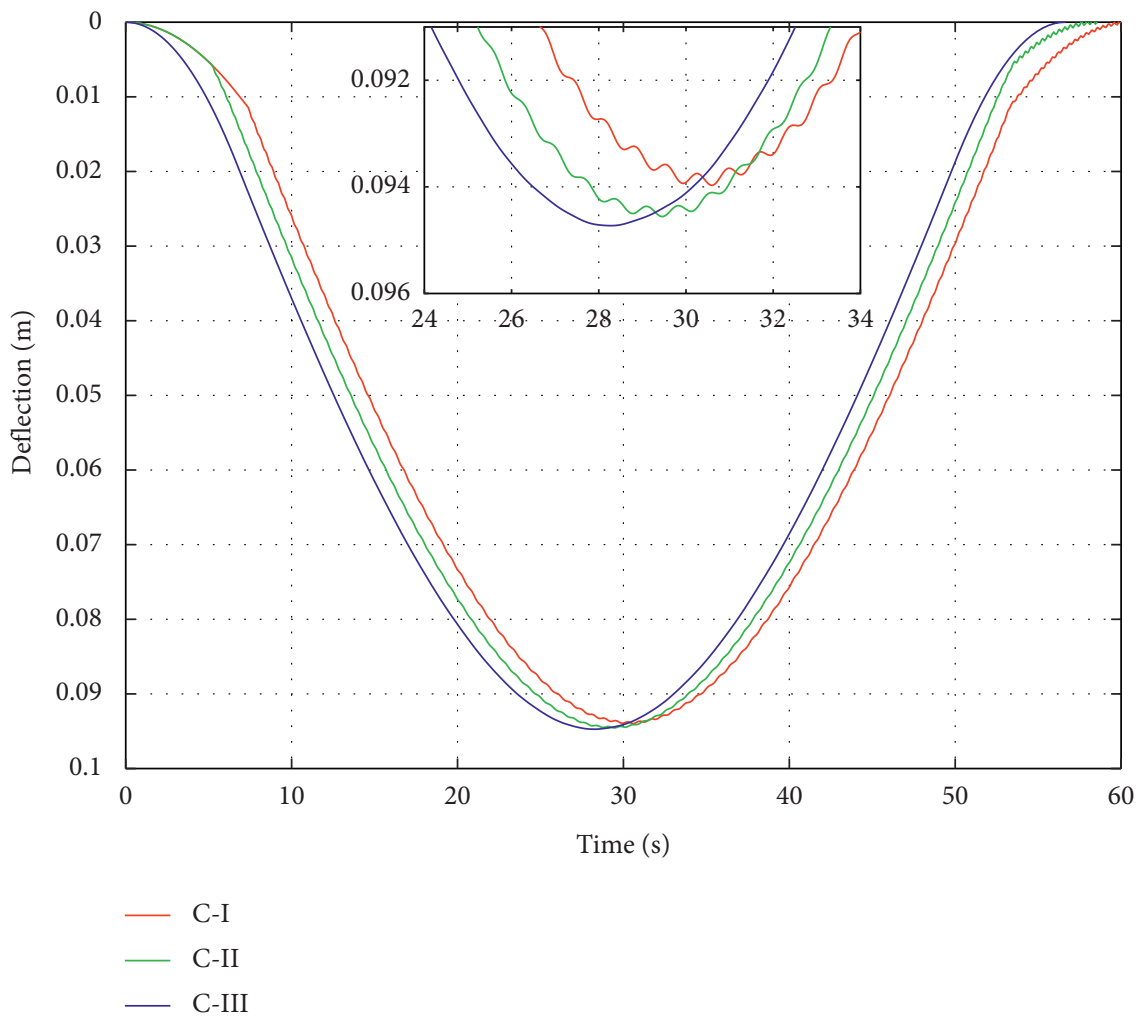

Figure 6: The midspan deflections of the beam.

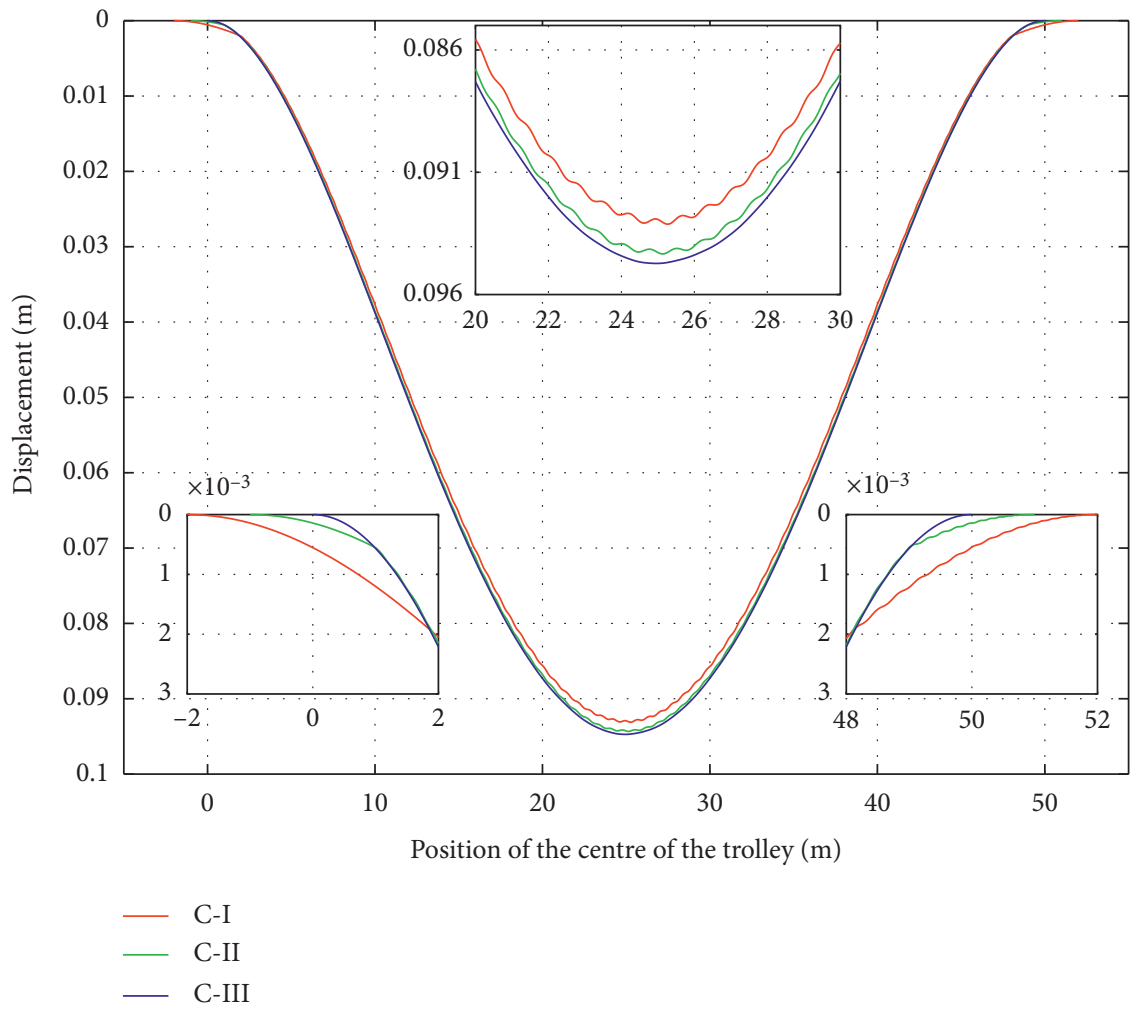

FIgURE 7: The displacement of the centre of the trolley. 


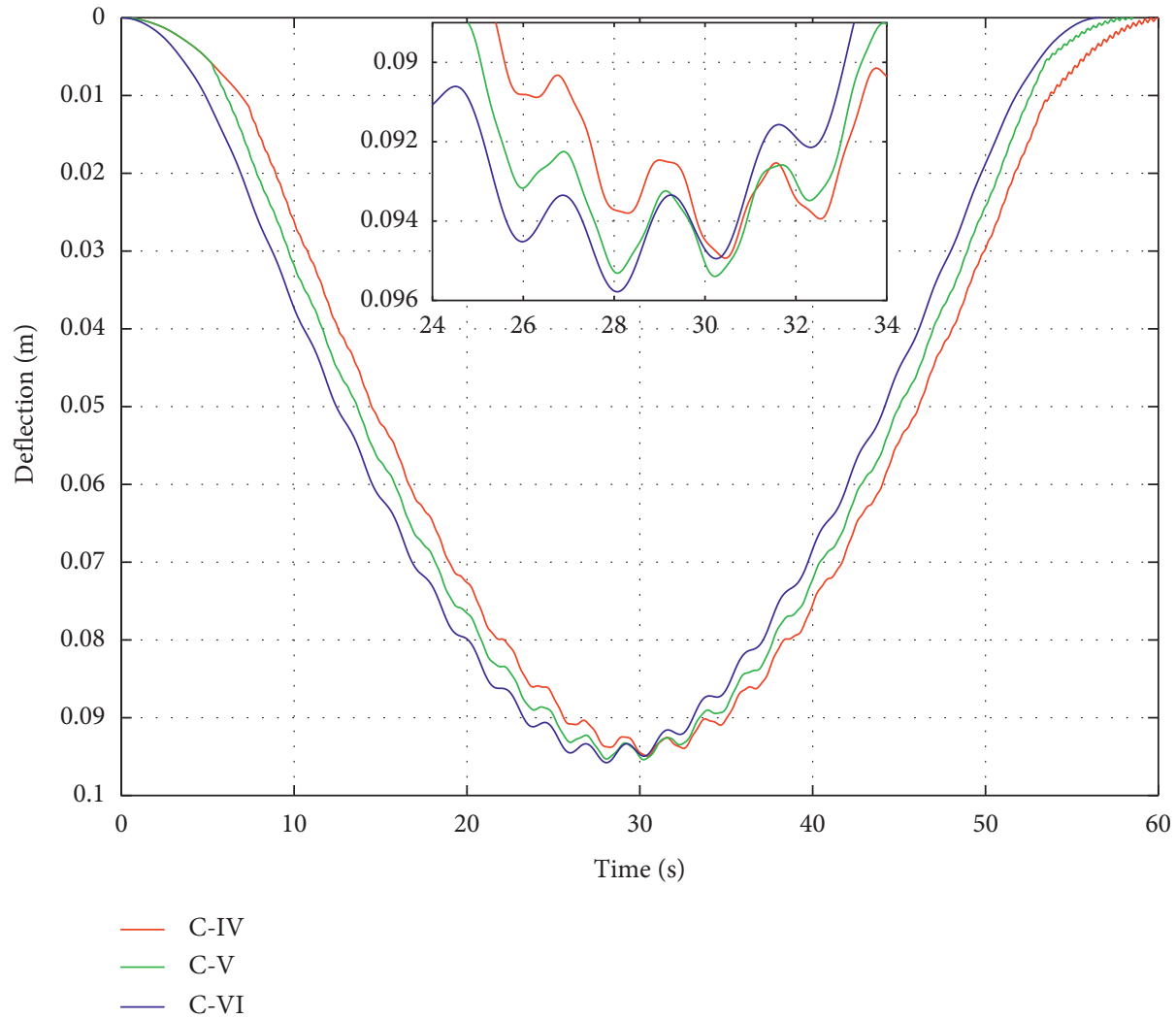

Figure 8: The midspan deflections of the beam.

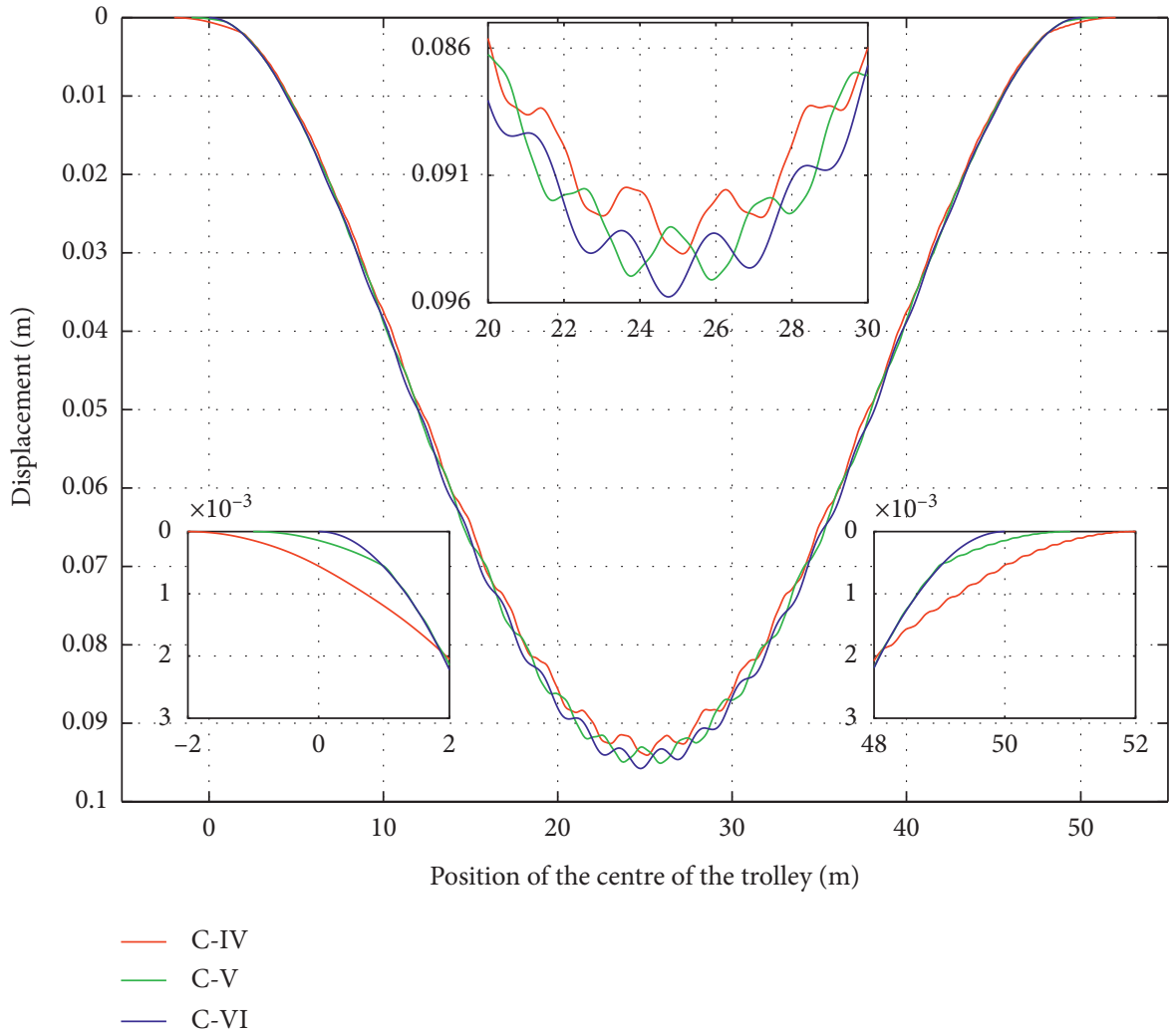

Figure 9: The displacement of the centre of the trolley. 

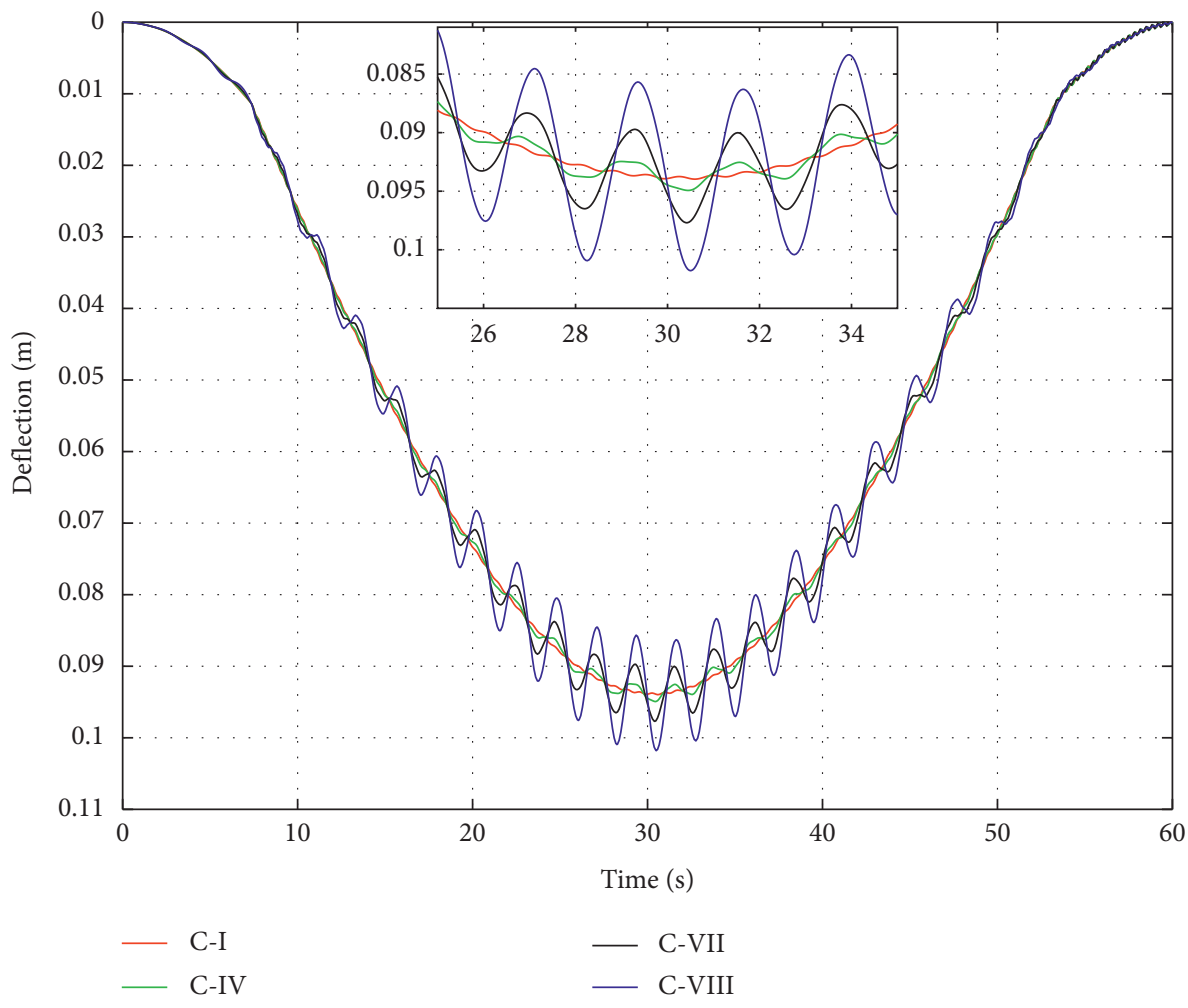

Figure 10: The midspan deflections of the beam.

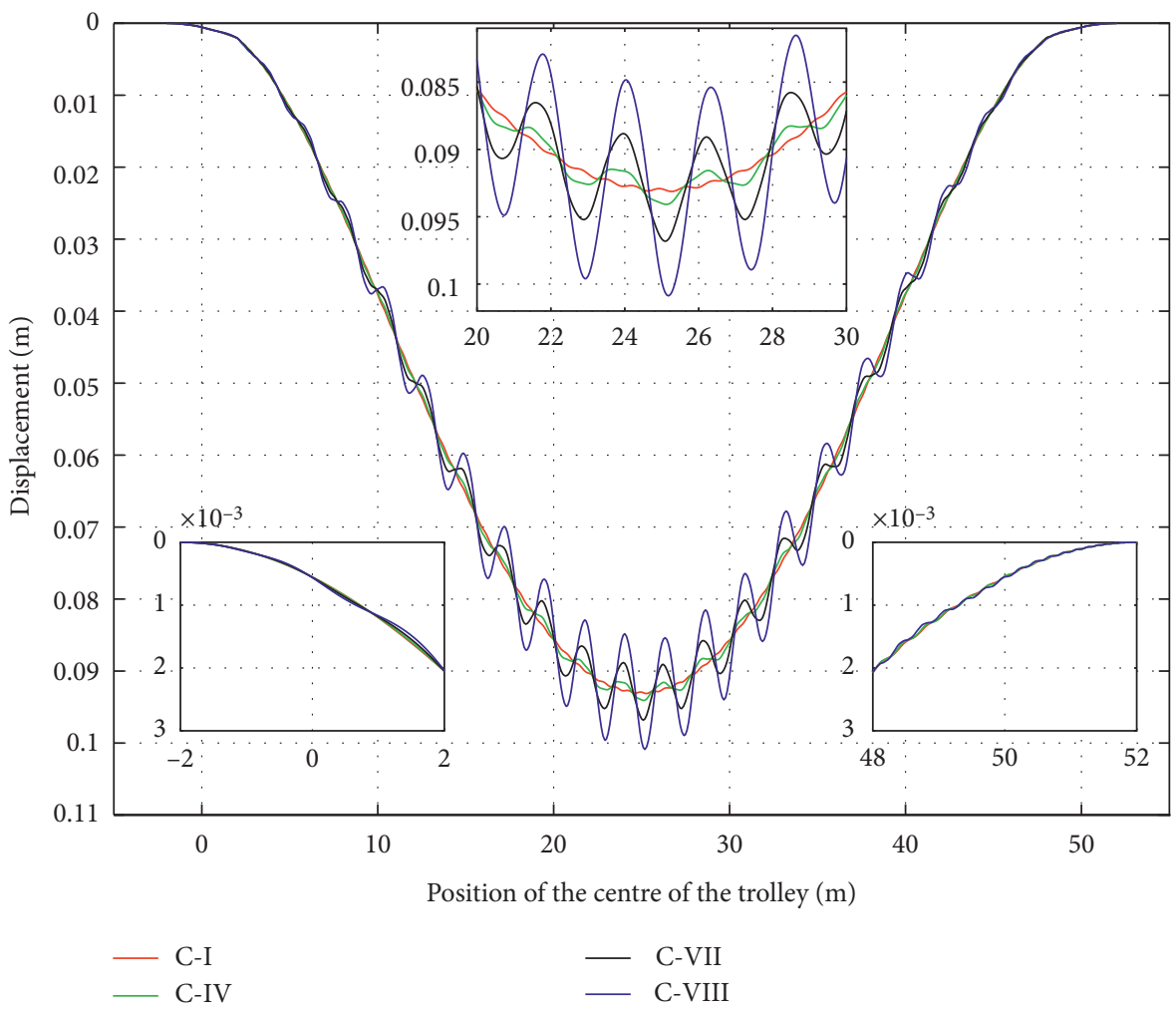

FIgURE 11: The displacement of the centre of the trolley. 


\section{Conclusions}

A novel moving load model for $2 \mathrm{D}$ crane systems of which the trolley has two axles was proposed in this paper. By comparing with existing papers, the proposed model was verified and can be considered as an extended version of comparative models. After the validation, the dynamics of a gantry crane system with a two-axle trolley were studied. On the basis of the forgoing analyses, one can draw the conclusions:

(1) There is small amplitude vibration of the beam under the action of the two-axle trolley. Thus, the dynamic responses of the beam subjected to a two-axle trolley is more accurate than that to a single-axle trolley.

(2) If the system parameters keep unchanged, the larger the axle base of the trolley, the smaller the maximum midspan deflection. Therefore, with a large total mass of the trolley and payload, increasing the length of trolley's axle base will decrease the maximum midspan deflection.

(3) The greater swing angle coincides with the greater midspan deflection. In order to avoid impact on the flexible beam, the swing angle should be controlled as small as possible.

\section{Data Availability}

The data used to support the findings of this study are available from the corresponding author upon request.

\section{Conflicts of Interest}

The authors declare that there are no conflicts of interest regarding the publication of this paper.

\section{Acknowledgments}

This study was supported by the National Natural Science Foundation of China (No. 51675450), Sichuan Science and Technology Program (No. 2019YFG0300), and Open Research Project of Technology and Equipment of Rail Transit Operation and Maintenance Key Laboratory of Sichuan Province (No. 2019YW001).

\section{References}

[1] N. Zrnic, V. M. Gašić, S. Bošnjak, and M. Đorđević, “Moving loads in structural dynamics of cranes: bridging the gap between theoretical and practical researches," FME Transactions, vol. 41, no. 1, pp. 291-297, 2013.

[2] D. C. D. Oguamanam, J. S. Hansen, and G. R. Heppler, "Dynamic response of an overhead crane system," Journal of Sound and Vibration, vol. 213, no. 5, pp. 889-906, 1998.

[3] H. Liu, W. Cheng, and Y. Li, "Dynamic responses of an overhead crane's beam subjected to a moving trolley with a pendulum payload," Shock and Vibration, vol. 2019, Article ID 1291652, 14 pages, 2019.

[4] Y. Xin, G. Xu, N. Su, and Q. Dong, "Nonlinear vibration of ladle crane due to a moving trolley," Mathematical Problems in Engineering, vol. 2018, Article ID 5756180, 14 pages, 2018.
[5] W. He, "Vertical dynamics of a single-span beam subjected to moving mass-suspended payload system with variable speeds," Journal of Sound and Vibration, vol. 418, pp. 36-54, 2018.

[6] N. Đ. Zrnić, K. Hoffmann, and S. M. Bošnjak, "Modelling of dynamic interaction between structure and trolley for mega container cranes," Mathematical and Computer Modelling of Dynamical Systems, vol. 15, no. 3, pp. 295-311, 2009.

[7] N. Đ. Zrnić, V. M. Gašić, and S. M. Bošnjak, "Dynamic responses of a gantry crane system due to a moving body considered as moving oscillator," Archives of Civil and $\mathrm{Me}$ chanical Engineering, vol. 15, no. 1, pp. 243-250, 2015.

[8] J.-J. Wu, "Transverse and longitudinal vibrations of a frame structure due to a moving trolley and the hoisted object using moving finite element," International Journal of Mechanical Sciences, vol. 50, no. 4, pp. 613-625, 2008.

[9] L. Ding, H. Hao, and X. Zhu, "Evaluation of dynamic vehicle axle loads on bridges with different surface conditions," Journal of Sound and Vibration, vol. 323, no. 3-5, pp. 826-848, 2009.

[10] N. D. Beskou and E. V. Muho, "Dynamic response of a finite beam resting on a Winkler foundation to al load moving on its surface with variable speed," Soil Dynamics and Earthquake Engineering, vol. 109, pp. 222-226, 2018.

[11] G. T. Michaltsos, "Dynamic behaviour of a single-span beam subjected to loads moving with variable speeds," Journal of Sound and Vibration, vol. 258, no. 2, pp. 359-372, 2002.

[12] W. P. Xie, J. Huang, J. L. Zhou, and W. He, "Vibration analysis of a suspension weight-bridge crane coupled system," Journal of Vibration and Shock, vol. 34, no. 15, pp. 127-132, 2015. 